\title{
AUTOMATION OF THE BUILDING PROCESS - RESEARCH AND DEVELOPMENT IN ISRAEL
}

\author{
Abraham Warszawski \\ Professor of Civil Engineering \\ Technion, I.I.T., and National Building Research Institute
}

\section{INTRODUCTION}

Research and Development, at the Technion, in the subject area, is directed towards integration and automation of the total building delivery process.

The automated process, depicted in Figure 1, receives as its input the owner's request, defined in general terms of function and scope. It produces, with the aid of norms and technical data from the data bank, first the preliminary and then the detailed design of the building. Then it continues with detailed design, and construction planning. The construction uses prefabricated components which are assembled and finished on site. The work progress is monitored by an information system. The process employs $\mathrm{CAD}$ and artificial intelligence for design and planning, and automation and robotization for production of components and their finishing on site.

The progress in this R\&D effort has been reported at the previous meetings of ISARC - in Haifa, Tokyo, San Francisco, Bristol, and Stuttgart. We will refer, in this report, also to other, non-conventional applications of robotics in Israel, which could be possibly adapted to construction use.

\section{ROBOTIC DEVELOPMENT}

The robotic development, at the National Building Research Institute, involves the Interior Finishing Robot, the automated crane, and the beginning of work on the horizontal finishing robot.

\section{Interior Finishing Robot (The TAMIR project)}

The main thrust of the robotic part of the general program described above, has been involved with the development of the multipurpose interior finishing robot TAMIR. The robot is designated to perform various finishing operations on the prefabricated building shell (structure and exterior envelope). It represents the generic class 1 of construction robots, as defined in [16],[17]. The program included, to date, the following modules:

1. Performance specifications and preliminary design of the robot and its components the arm, the carriage, the sensors, the effectors and the control system. The findings are described in [19].

2. Adaptation of building technologies to robotic constraints. The main works which have been adapted in this context were partitions building, plastering, floor finishing. Several additional works are also being adapted to robotic requirements. The project is described in [3]. 


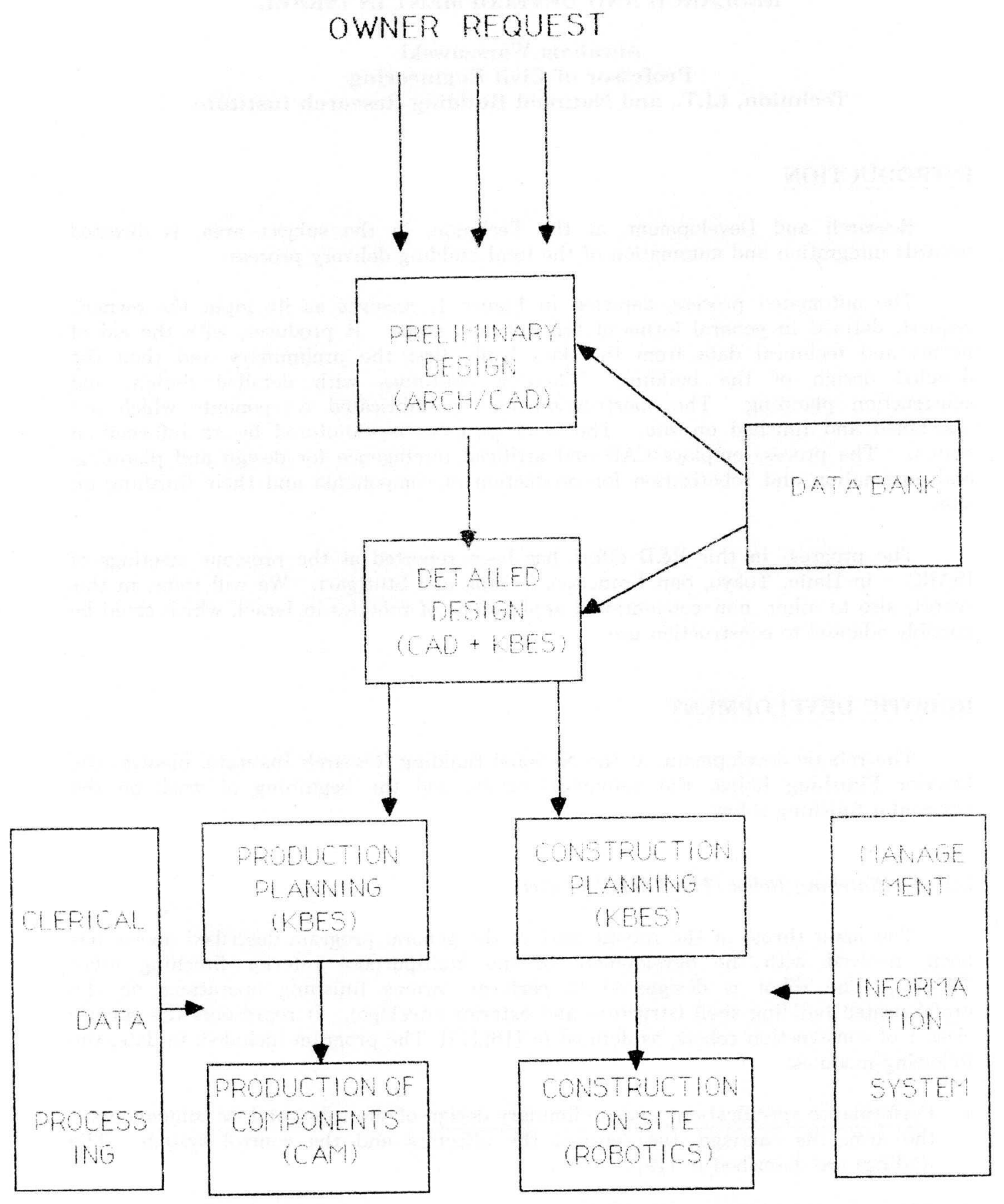

Figure 1-Automated building deliverv svstem 
3. Analysis of optimal configuration in terms of the robot productivity, cost, and ease of operation. The preferred solution has been determined with the aid of computer simulation and measurement of performance of various configuration alternatives. The study is described in [15].

4. Planning of robotized work. Within the context of this study a computerized procedure has been developed for analysis of the feasibility of robot employment to different types of buildings. The study is described in [2].

5. Testing of physical performance of automated tasks with a small robot (Scorbot of Eshed Robotec, arm reach of $0.60 \mathrm{~m}$ and payload of $1.0 \mathrm{~kg}$ ) adapted to building works. The experiments are described in [1].

6. Testing of physical performance of automated tasks with a full scale robot ( $\mathrm{S}-700$ of GMF, reach of $1.50 \mathrm{~m}$ and payload of $30 \mathrm{~kg}$ ) adapted to building works. The robot can perform various finishing tasks - painting, plastering, tile setting, partitions, building and others. It will employ several types of sensors - for avoidance of obstacles, for materials handling, for mapping and navigation and for identification of openings. The robot is described in [10], and [11].

7. Economic analysis of performance. The analysis involved the three applications which were developed and studied, namely tiling, painting/plastering, and partitions building, and included comparison of robotic vs. manual productivity and construction cost. The main findings of this study are presented in [12].

8. Autonomous control system for the finishing robot employs ultrasonic, or laser sensors for mapping of an unknown building environment, and artificial intelligence for planning of the work procedures. The progress in this study is described in [14].

9. Detailed design of the robotic system. The development, to date, used mostly off-the-shelf robot components. These components can be improved in terms of their effectiveness and material saving, if specifically designed in view of the knowledge accumulated within the course of this program.

\section{Automated crane}

The automated crane represents the generic class 2 of construction robots as defined in [16]. The objective of the automation is to improve the productivity and accuracy of the assembling of the prefabricated shell of the building. The first stage, which included feasibility study, has been described in [9]. The present stage includes automation of a rectangular/gantry crane (of its three axes), and will be later extended to the jointed/tower crane.

\section{Horizontal finishing robot}

The floor finishing robot constitutes the generic class 4 of construction robots, as defined in [16]. Work has been started on the conceptual development of a multipurpose finisher which will include a carrier and an exchangeable tool. The robot will be conceived in the first stage, for floor tiling, and possibly use as a carrier the AGV described in [6]. 


\section{AUTOMATED BUILDING PLANNING AND DESIGN}

The purpose of this program is to automate the design and planning process of an industrialized building, as depicted in figure 1 . The process includes the following stages:

a. Preparation of brief.

b. Generation of preliminary design.

c. Performance evaluation of preliminary design.

d. Adaptation of the design to industrialization.

e. Construction planning.

Several projects have been completed and are in progress on subjects c,d,e. They are as follows:

Performance evaluation of preliminary design - an expert system which evaluates the thermal acoustic and fire resisting performance of a given building design. The system is described in [18].

Adaptation of design to industrialization - an expert system which generates a detailed design and cost estimate of prefabricated elements on the basis of preliminary conventional design of a building. The system is described in [8].

Construction planning - Two expert systems have been developed for this purpose. One of them - CONSCHED described in [ ] deals with midrise residential buildings. It generates a list of activities necessary to complete a given building, the resources required for the completion and a work progress schedule. The other, described in [7], assists in selection and location of cranes on a building site.

A third system, which deals with construction planning of tall buildings, is now under development.

\section{OTHER RELATED SYSTEMS}

Robotic system with an inflatable arm

The robot is under development in the Faculty of Mechanical Engineering of the Technion, I.I.T. It employs, for the arm, a thin cylindrical shell made of elastomer woven fabric. The main advantages of such arm, and its potential use in construction are:

a. a very high payload to weight ratio.

b. compact packaging and ease of deployment.

c. safer operation - less damage in case of collision.

The robot is described in [5].

\section{Flexible manufacturing system}

An extensive and very sophisticated flexible manufacturing system is employed by an Iscar Co for production of special steel alloys. Two features of this system are noteworthy with reference to potential use in construction: 
a. sturdy automated vehicles which could be used as tool carriers or servers in construction.

b. sophisticated sensor-guided quality control system. The system samples production units, tests them, evaluates the results, and calibrates the performance as needed.

\section{Automated self-navigating vehicle}

An automated vehicle has been developed at the Faculty of Mechanical Engineering of the Technion. The vehicle is equipped with sensor and control system, which allows it to navigate its way towards the specified target, and omit possible obstacles on its way. The vehicle is described in [ ].

\section{Melon picking robot}

The robot, under development at the Vulcani Institute in Bet Dagan, has a rectangular configuration. It moves over a cultivated lot, identifies the fruit on the ground and picks it.

Three features of the robot are noteworthy:

a. vision sensors which identify the fruit to be picked.

b. multi-arm system for fruit picking.

c. control algorithm for minimization of the picking time.

\section{BIBLIOGRAPHY}

1. Argaman, H. and Warszawski, A., "Teaching Robotics in Building", Proceedings of the Fourth International Symposium on Robotics and Artificial Intelligence in Building Construction", Haifa, Israel, 1987.

2. Argaman, H., "Development of a Method for Robotization Planning on the Building Site", Unpublished D.Sc. dissertation, Technion, I.I.T., Haifa, Israel, 1989.

3. Bentur, A. and Puterman, M., "Adaptation of Special Materials for the Development of Construction Automation", Proceedings of the Fourth Internaional Symposium on Robotics and Artificial Intelligence in Building Construction, Haifa, Israel, 1987.

4. Edan, Y. and Miles, G.E., "Design of an Agricultural Robot for Harvesting Melons", Symposium of American Society of Agricultural Engineers, Albuquerque, NM, 1991.

5. Grossman, G. et al, "Robotic System Based on Inflatable Structures", Faculty of Mechanical Engineering, Technion, I.I.T., Haifa, Israel, 1992.

6. Lentz, E. and Farhana, D., "AGV Location Using Triangulation", Ullman Robotics Center, Technion, I.I.T., Haifa, Israel, 1990.

7. Peled, N. and Warszawski, A., "Expert System for Crane Selection and Location", Proceedings of the Fourth International Symposium on Robotics and Artificial Intelligence in Building Construction, Haifa, Israel, 1987.

8. Retik, A. and Warszawski, A., "Automated Design of Prefabricated Building", Proceedings of the Second Conference on Applications of AI to Civil Engineering, Oxford, 1992. 
9. Rosenfeld, Y. and Berkovitz, S., "Automation of Existing Tower Cranes - Economic and Safety Examination", Proceedings of the Sixth International Symposium on Automation and Robotics in Construction, San Francisco, 1988.

10. Rosenfeld, Y., Warszawski, A. and Zaijcek, U., "Robotic Performance of Interior Finishing Works", Proceedings of Seventh International Symposium on Automation and Robotics in Construction, Bristol, UK, 1990.

11. Rosenfeld, Y., Warszawski, A. and Zaijcek, U., "Robotic Performance of Interior Finishing Works: Development of Full-Size Applications", Proceedings of Eighth International Symposium on Automation and Robotics in Construction, Stuttgart, 1991.

12. Rosenfeld, Y., Warszawski, A. and Zaijcek, U., "Economic Evaluation of Robotic Work", Proceedings of Ninth International Symposium on Automation and Robotics in Construction, Tokyo, 1992.

13. Shaked, U. and Warszawski, A., "CONSCHED - An Expert System for Construction Planning", ASCE Journal of Construction Engineering and Management, September 1993.

14. Shohet, I., Warszawski, A. and Rosenfeld, Y., "Autonomous Control System for Interior Finishing Robot", Proceedings of Ninth International Symposium on Automation and Robotics in Construction, Tokyo, 1992.

15. Warszawski, A. and Navon, R., "Robot for Interior Finishing Works", ASCE, Journal of Construction Engineering and Management, September, 1991.

16. Warszawski, A., "Industrialization and Robotics in Building", Harper and Row, New York, 1990.

17. Warszawski, A. and Sangrey, D., "Application of Robotics to Building Construction", ASCE Journal of Construction Engineering and Management, 1986.

18. Wiesel, A. and Becker, R., "Integration of Performance Evaluation in CAD", Proceedings of the SUNY Buffalo 3rd International Symposium on CAD, Buffalo, 1990.

19. Yavnai, A., Warszawski, A. and Navon, R., "A Preliminary Design of an Interior Finishing Robot, Building Research Station, Technion, I.I.T., 1986. 